\title{
A DFT study of the interaction of bimetallic Pt-Sn with Ethanol
}

\author{
Irineo-Pedro Zaragoza ${ }^{1, *}$, Ruben Santamaria ${ }^{2}$, Xim Bokimi ${ }^{2}$, V. Estrella ${ }^{1}$ and Víctor Castellanos ${ }^{1}$ \\ ${ }^{1}$ Tecnológico Nacional de México, Campus Instituto Tecnológico de Tlalnepantla, División de Estudios de \\ Posgrado e Investigación, Av. Mario Colín S/N, La Comunidad, Tlalnepantla de Baz, C.P. 54700, México. \\ ${ }^{2}$ Instituto de Física, Universidad Nacional Autónoma de México, Cd. México A.P. 20-364, C.P. 01000, México.
}

\begin{abstract}
The study of the interaction of metallic with ethanol is important to understand alternative forms of generating electric energy. In this context, the interaction of the bimetallic Pt-Sn with ethanol is investigated using molecular dynamics in combination with density functional theory. Different interaction channels are determined by changing the initial conditions in the simulation, however, only one of them results in the catalysis of ethanol, producing in the fragmentation $\mathbf{O H}$ and $\mathbf{H}$. The changes of the electronic energy, kinetic energy, electron density, HOMO and LUMO molecular orbitals and charge distribution some the relevant variables are used to characterize the interaction of the compounds with time. The results indicate that the $\mathrm{Sn}$ atom of the bimetallic compound plays a major role in the catalytic process.
\end{abstract}

Keywords: bimetallic, ethanol, molecular dynamics, density functional theory, reaction.

\section{Introduction}

Hydrogen is considered one of the main energy sources of the future. The fuel cell is the optimal device to convert the energy stored in hydrogen into electric energy ${ }^{1}$. There are different types of fuel cells, which are classified according to the transformation processes ${ }^{2}$. The one of our interest is the fuel cell based on the exchange of hydrogen because it produces protons which in turn generate electric energy efficiently ${ }^{3}$. The mechanism on the conversion of energy departs from ethanol; an alcohol considered a donor of hydrogen, and where a catalytic process occurs to extract the hydrogens of ethanol that are used in the fuel cell ${ }^{4}$. In particular, a specially designed membrane produces the required ions from the hydrogen with the purpose of creating a potential energy difference between the anode rod and the cathode rod in the fuel cell ${ }^{5}$. This mechanism classifies as an important renewable and friendly energy process with many applications in our daily life; such as in the transportation of people and goods, considered one of the strongest energy consumers.

The ethanol is easy to store at a lower risk of the manipulation. The ethanol is usually obtained from the agriculture of sugar cane, maize, and microbial fermentation processes; thus, it is abundant becoming a low-cost energy source ${ }^{6}$. There are many investigations nowadays to understand and improve the electronegative reaction that involves ethanol and other similar alcohols ${ }^{7}$. Some of these studies are concentrated on using platinum $(\mathrm{Pt})$ as an

*Corresponding author: Irineo-Pedro Zaragoza

Email address: izaragoza@ittla.edu.mx

DOI: http://dx.doi.org/10.13171/mjc66/01712181415-zaragoza active catalyst to break the $\mathrm{O}-\mathrm{H}$ and $\mathrm{C}-\mathrm{H}$ bonds. At the experimental level, this is done using the ethanol steam reforming process via the dehydrogenation of ethanol with temperature ${ }^{8,9,10}$.

A relevant point to consider in the energy transformation process using ethanol is the role played by the transition metals. These metals actively participate in the dehydrogenation catalytic process in the step previous to the energy transformation into electricity. Nano-particles of $\mathrm{Pt}$ are dispersed in the fuel cells along the anode and the cathode rods to improve the catalytic efficiency. There are investigations on the dispersion of $\mathrm{Pt}$ and its relationship with the effectiveness of the catalytic process. The investigations have used different spectroscopic methods to evaluate the ethanol electro-oxidation ${ }^{11}$. The different dispersion densities of the nano-particles exhibit different reactions for the different types of fuels ${ }^{12}$. Yet, the most investigated metals are $\mathrm{Pt}$, and $\mathrm{Pd}$, with $\mathrm{Sn}$ doping in the rods to increase the chemical activity ${ }^{13}$.

The theoretical studies have made use of density functional theory (DFT) to investigate the catalytic electro-oxidation reaction of ethanol mixed with water and the Pt-Sn alloy ${ }^{14}$. Ethanol is the simplest molecule that contains the $\mathrm{C}-\mathrm{C}$ and $\mathrm{C}-\mathrm{O}$ single bonds. In these studies, the authors find that the catalytic reaction of ethanol with $\mathrm{Pt}$ and $\mathrm{Pt}-\mathrm{Sn}$ produce $\mathrm{C}_{2} \mathrm{H}_{4}$ and $\mathrm{CO}$, reproducing the experimental results reported from microcalorimetric and infrared spectroscopic measurements ${ }^{15}$. There are also other 
DFT studies on the transformation of ethanol to determine the catalytic activity of $\mathrm{Pt}_{3} \mathrm{M}$ alloys, where $\mathrm{M}=\mathrm{Pt}, \mathrm{Ru}, \mathrm{Sn}, \mathrm{Re}, \mathrm{Rh}$, and $\mathrm{Pd}^{16}$.

The methanol and ethanol catalysis present several important reactions in bimetal presence, unlike when one considers only Platinum element. The reaction products that have been reported are hydrogen, carbon monoxide and carbon dioxide, these latter promote catalytic poisoning of Pt and parallel effect is the decreased activity. Studies show the reaction products by $\mathrm{Pt}-\mathrm{Ru}$ and $\mathrm{Pt}-\mathrm{Sn}$ bimetals do not directly affect the Platinum but are still obtained equivalent reaction products favoring the activity. The catalysis by the bimetal promotes intermediary reactions that require more detailed to be understood. In the case of the methanol experimental measurements as the reflectance infrared spectroscopy indicate that the bimetal Pt$\mathrm{Ru} / \mathrm{C}$ as a catalyst is more active due to their greater capacity to dehydrogenate of methanol and ethanol electro-oxidation is by the bimetal $\mathrm{Pt}-\mathrm{Sn} / \mathrm{C}$, in both cases show higher catalytic activity than the $\mathrm{Pt} / \mathrm{C}$, indicating that $\mathrm{Pt}-\mathrm{Sn} / \mathrm{C}$ in comparison with $\mathrm{Pt} / \mathrm{C}$ for the electro-oxidation of ethanol show best activity. In addition to $\mathrm{Sn}$ significantly decreases the effect of adsorbed CO poisoning ${ }^{17-22}$.

In this work, we investigate the interaction of ethanol with the bimetallic Pt-Sn by combining DFT with molecular dynamics. The approach attempts to model in simple form the catalytic process that occurs in a fuel cell under the supposition that the catalytic process occurs at a local level. We observe the dissociation of the ethanol molecule to produce hydrogen and rest of atoms. The most important reaction channel is reported by discussing the selectivity of the bimetallic catalyst, the charge transfer between the reactants, and the energy changes during the breaking of bonds.

\section{Molecular Models and Methodology}

The $\mathrm{Pt}-\mathrm{Sn}$ and ethanol molecules were separately obtained through a calculation of geometry optimization. These molecules were used to perform the DFT calculations of the molecular dynamics for the different paths of interaction. The calculations included the effects of electronic correlation in addition to corrections of the orbital spin to a level of theory of DFT, by using a respective module NWChem ${ }^{23}$. The DFT gradient method of correction for the exchange as the functional of Becke $88^{24}$ and the gradient of correction for correlation with the functional of LeeYang-Parr (LYP) ${ }^{25}$ make up the functional Becke88 and LYP that are used in the geometry optimization, as well as the studies of the dynamic interactions.

Density Functional Theory (DFT) is appropriated to determine structural and changes of electronic property including good accuracy methods that due to electronic correlation and spin-orbital corrections using Non-Local Density Approximation
(NLDA) and exchange energy functional of the corrected gradient with asymptotic behavior. When the nonlocal version of DFT is compared with the local approximation of DFT, it is found that the nonlocal approach gives an improved prediction of the electronic properties and interaction energies of molecules, also, the higher capacity to explain the anisotropy of the charge distribution ${ }^{26}$. In general, the nonlocal DFT results are found in good agreement with the experimental measurements. The DZVP basis set was used in all calculations for light atoms, this basis set should not introduce artificial electronic distortions. This computational level has shown good results for geometric optimization of molecules that contain hydrocarbons with methyl groups ${ }^{27}$. In the case of $\mathrm{Pt}$ and $\mathrm{Sn}$, the LAN2DZ pseudo potential was used. The interactions between ethanol molecule and Pt-Sn were studied by molecular dynamic interaction, starting with the initial positions. A maximum cartesian step of 0.0015 Bohr and a convergence of 0.0015 Hartree/Bohr in the energy gradients are conveniently chosen. The molecular dynamics simulation technique is important because it allows knowing the dynamical nature of the nuclear particles since they help to gain a deeper understanding of the mechanism of dissociation and binding bond reaction over atom system ${ }^{28}$. These reactions are simulated by Born-Oppenheimer approximation method ${ }^{29,30}$. A neutral charge for the whole system is considered for this case, the spin multiplicity is 1 . The electronic wave function is obtained by taking into account that electrons are immersed in a field of instantaneously fixed nuclei, whereas the nuclear particle is immersed in an average electronic field. The heavy masses and very short spatial extension of the nuclear particles compared to those of electrons let us simplify the problem by considering the nuclei as a classical particle. In order to this happen, each nucleus follows a Newtonian trajectory due to quantum forces derived from the electron potential plus the electrostatic force exerted by the other nuclear particles. The time step in the dynamics is $1 \mathrm{fs}$. The self-consistent approach is considered finished when a convergence of $10^{-5}$ as in the energy and density are obtained.

\section{Results and Discussion}

For the molecular dynamics study, we considered that initially the metallic biatomic molecule and the ethanol molecule are far away from each other, simulating a gaseous state of the system: there was no interaction between them (Fig 1). Energy values were calculated in every step as the molecules came up to the collision. Changes in energy value were caused by changes in the molecular structure of the ethanol molecule as it depended on the collision direction between the metallic biatomic molecule and the ethanol molecule. 
The fragment resultant obtained during the interaction between the components of the system are shown in Fig 2. Pt atom is the principal promoter
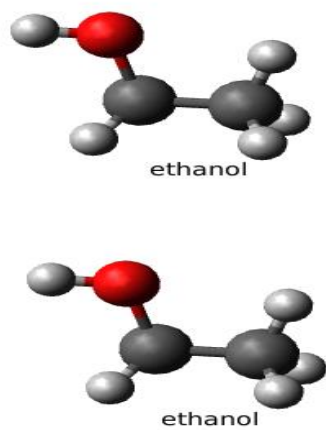

a)

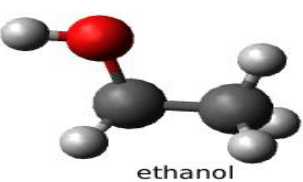

b) of the catalysis of ethanol. Nevertheless, the role of the Sn was important, although it, by itself does not induce fragmentation of the ethanol molecule.
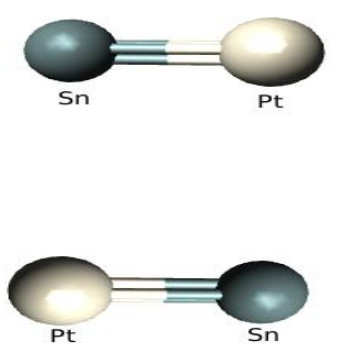

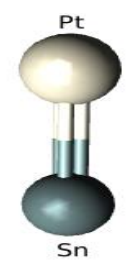

c)

Figure 1. Initial positions for the dynamic interaction calculations between ethanol molecule and $\mathrm{Pt}-\mathrm{Sn}$ diatomic with a preferential path of the $\mathrm{CH}_{3}$ moiety to find a possible reaction mechanism; a) in the direction of $\mathrm{Sn}, \mathrm{b})$ in the direction of $\mathrm{Pt} ; \mathrm{c}$ ) in the direction of center $\mathrm{Pt}$ and $\mathrm{Sn}$.

Impact of the ethanol molecule on Sn atom.

At the beginning, ethanol molecule was faced towards bimetal cluster in a direction to $\mathrm{Sn}$ atom with a considerable separation. As time went by, the ethanol molecule approached the bimetal until clashing, suffering different structural changes as well as bond elongations, but, in the end, the ethanol molecule structure did not change. The energy changes in the range of $0-70$ fs had two maxima: the first one corresponds to the collision of a $\mathrm{CH}_{3}$ moiety with the tin atom, repulsion forces observed without bond breaking. The second energy maximum was associated with the repulsion of $\mathrm{CH}_{3}$ at the same time ethanol molecule shows to a rotation being oxygen before $\mathrm{Sn}$ atom and atom vibrations of rest of ethanol molecule as shown in Fig. 2. The results show that the bimetallic Pt-Sn does not generate molecular structure transformation of ethanol during the interaction with the tin atom.

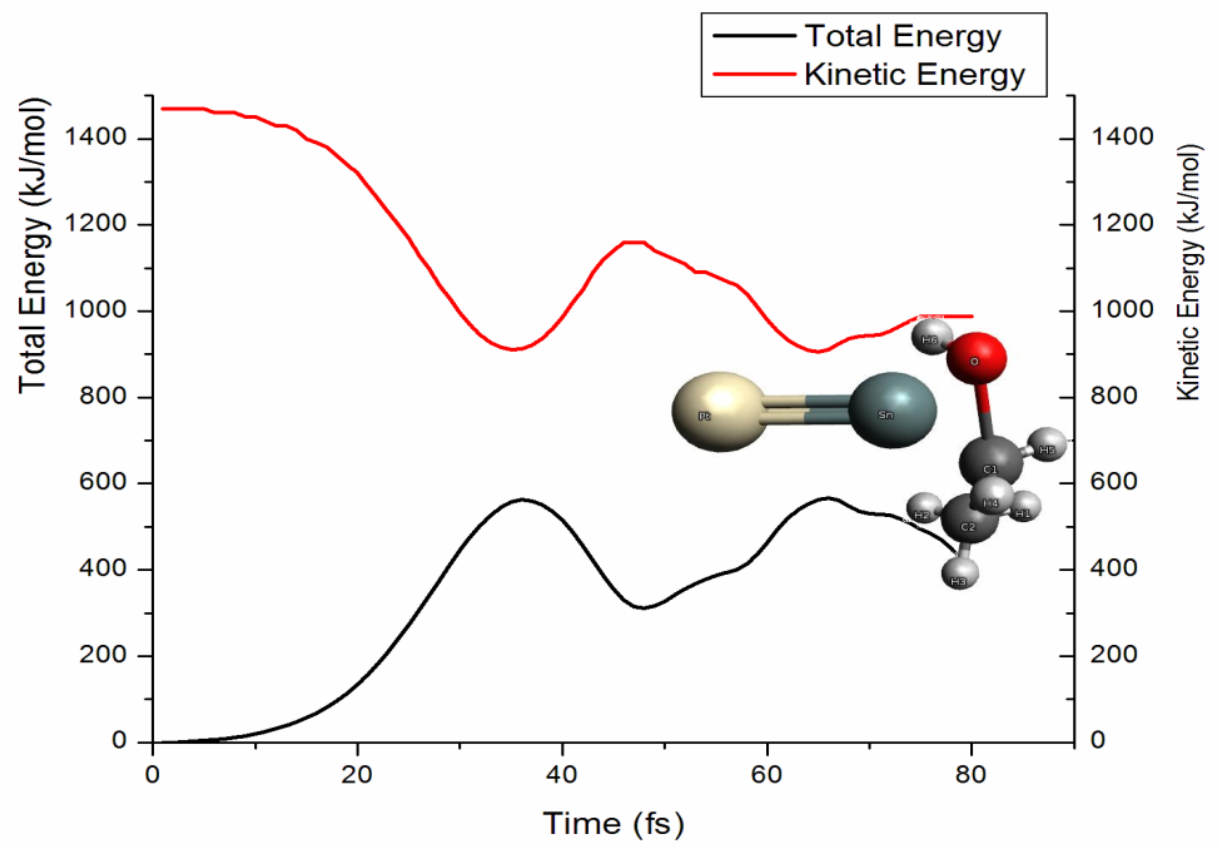

Figure 2. Total and kinetic energy in the interaction between bimetallic Pt-Sn and ethanol molecule. There are not changes in the ethanol molecule when the impact occurred on Sn atom. 
The kinetic energy values in Figure 2 are assigned to describe ethanol movement approaching and interacting with the bimetal until coming to a stop, indicated by a minimum showing a purely repulsive. The ethanol continues moving with atomic vibrations moments later and walks away.

The Mulliken analysis of the charges shows interesting charge distributions for the considered molecules. The first one is constituted by the bimetallic $\operatorname{Pt}(10)-\operatorname{Sn}(11)$ and the second one by the ethanol $\mathrm{H}(9) \mathrm{O}(6) \mathrm{C}(1) \mathrm{H}(7,8) \mathrm{C}(2) \mathrm{H}(3,4,5)$. Initially, both atom arrangements had charge zero. As time went by, their charges changed: the charge of the metallic cluster decreased to a range between 0 and $70 \mathrm{fs}$, whereas that of the ethanol molecule increased. Finally, after 70 fs no charge exchange occurred.

\section{Impact of the ethanol molecule on Pt atom.}

The initial system considers the $\mathrm{CH}_{3}$ moiety of the ethanol molecule and the Pt-Sn for the dynamic interaction in the direction of the $\mathrm{Pt}$ atom. In comparison to the previous case, the movement of the ethanol molecule was the same velocity in every step. This interaction brought $\mathrm{C}-\mathrm{H}$ bond generating the following products: $\left(\mathrm{HOC}_{2} \mathrm{H}_{4}, \mathrm{H}\right)$. Fig. 3 shows the total energy changes that occurred during the first $70 \mathrm{fs}$; the maxima and minimum were found. The first point in the interval between 0 and $30 \mathrm{fs}$ the ethanol molecule comes near to Pt atom, in 31 to 45 fs: The energy values increase up to a maximum and corresponds to expulsion of hydrogen ethanol with an energy of $420 \mathrm{~kJ} / \mathrm{mol}$ after that the energy decrease until a minimum values of energy, when was generated of the $\left(\mathrm{C}_{2} \mathrm{H}_{4} \mathrm{OH}, \mathrm{H}\right)$, in the interval between $45 \mathrm{fs}$ and $55 \mathrm{fs}$, after that, ethanol is deformed and picks up the movement with a turn to acquire the latest atomic conformation to this correspond to an increase in the values of the energy during the interval between 55 and 70 fs. The kinetic energy plot describes how ethanol movement was, stopping when there is a minimum value and the rotation promotes movement at the time of purchase another conformation to finally take ethanol conformation.

The kinetic energy values in Figure 3 when approached the bimetal promotes the dissociation of hydrogen with atomic vibrations this is indicated by a minimum value, considered as the complement of the potential energy.

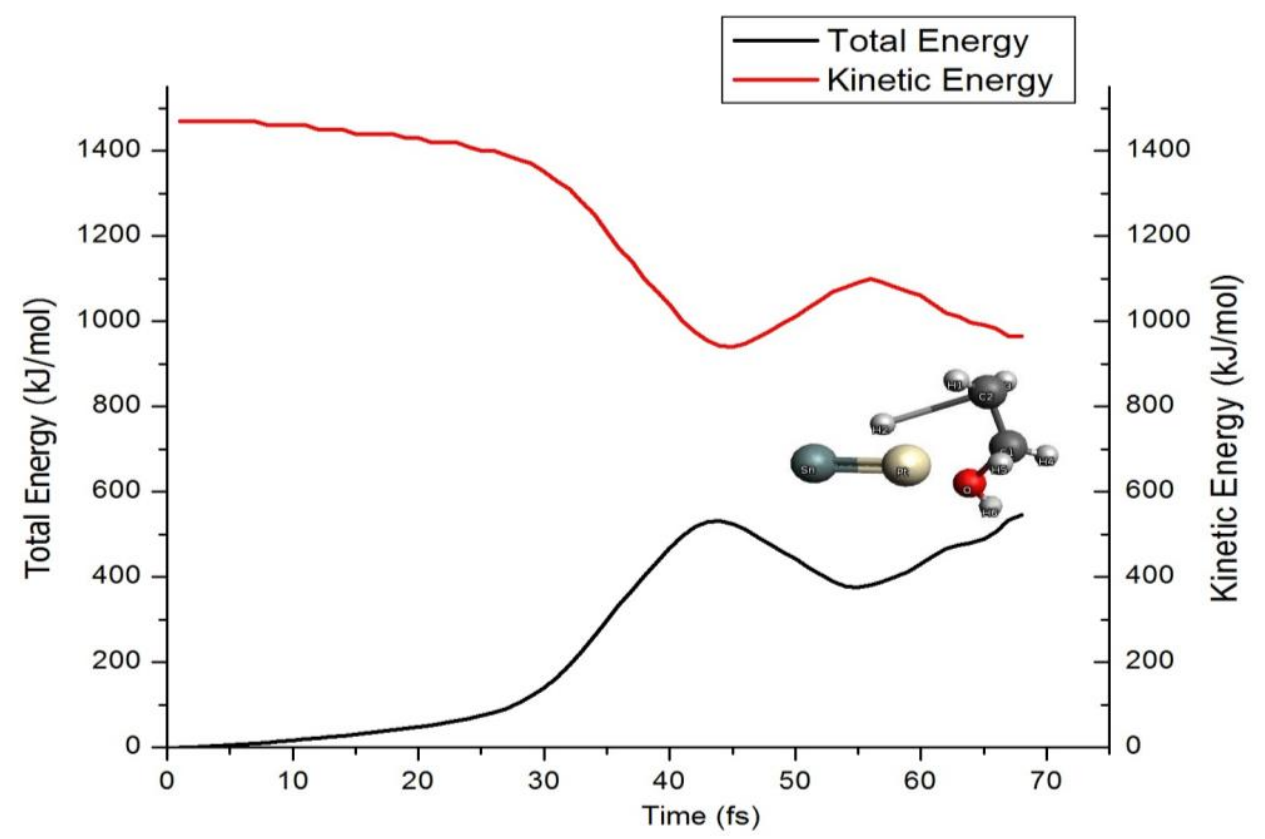

Figure 3. The total and kinetic energy values (left, black line) and (right, red line) respectively during the process of dynamic interaction of ethanol with the $\mathrm{Pt}-\mathrm{Sn}$, when the impact occurred on $\mathrm{Pt}$ atom.

The Mulliken population analysis shows that charge is distributed during the generation of the breaking bond which is the product of the reaction: $(\operatorname{Pt}(11) \operatorname{Sn}(10)-(22.05 \mathrm{e}))$, and $(\mathrm{H}(4)-(0.75 \mathrm{e}))$ in the time interval between 0 to $30 \mathrm{fs}$. The numbers in parentheses correspond to the number of atoms and the corresponding partial charge value. In the time interval between 35 and $45 \mathrm{fs}$ it is observed that $\mathrm{H}(4)$ atom presented a decrease of charge $(0.17 \mathrm{e})$, whereas that of $\mathrm{Pt}(11) \mathrm{Sn}(10)$ increased to $(-0.17 \mathrm{e})$; the charge of the $\mathrm{H}(7,8) \mathrm{C}(1) \mathrm{C}(2) \mathrm{H}(3,5) \mathrm{OH}$ moiety did not change. In the time around of $70 \mathrm{fs}$ the $\mathrm{Pt}(11) \mathrm{Sn}(10)$ have charge of (22.04 e), and H(4) with (0.92 e).

\section{Impact of the ethanol molecule perpendicular to the bond between Pt and Sn atoms. \\ In this case, the bimetallic cluster position was perpendicular to ethanol interacting with the $\mathrm{CH}_{3}$ moiety which moved in a direction to the center of the Pt-Sn bond; the separation between atomic clusters was large. The reactions that occur during}


the interaction due to $\mathrm{Pt}-\mathrm{Sn}$ affected the ethanol bonds $\mathrm{C}-\mathrm{H}$, producing the fragments $\left(\mathrm{HOC}_{2} \mathrm{H}_{4}, \mathrm{H}\right)$. Fig. 4 shows that the energy values present a maximum in the $70-95 \mathrm{fs}$, its corresponds to ejecting one hydrogen ethanol with an energy of 400 $\mathrm{kJ} / \mathrm{mol}$ considering the range time 80 and $95 \mathrm{fs}$.

The initial values of the distribution of charge

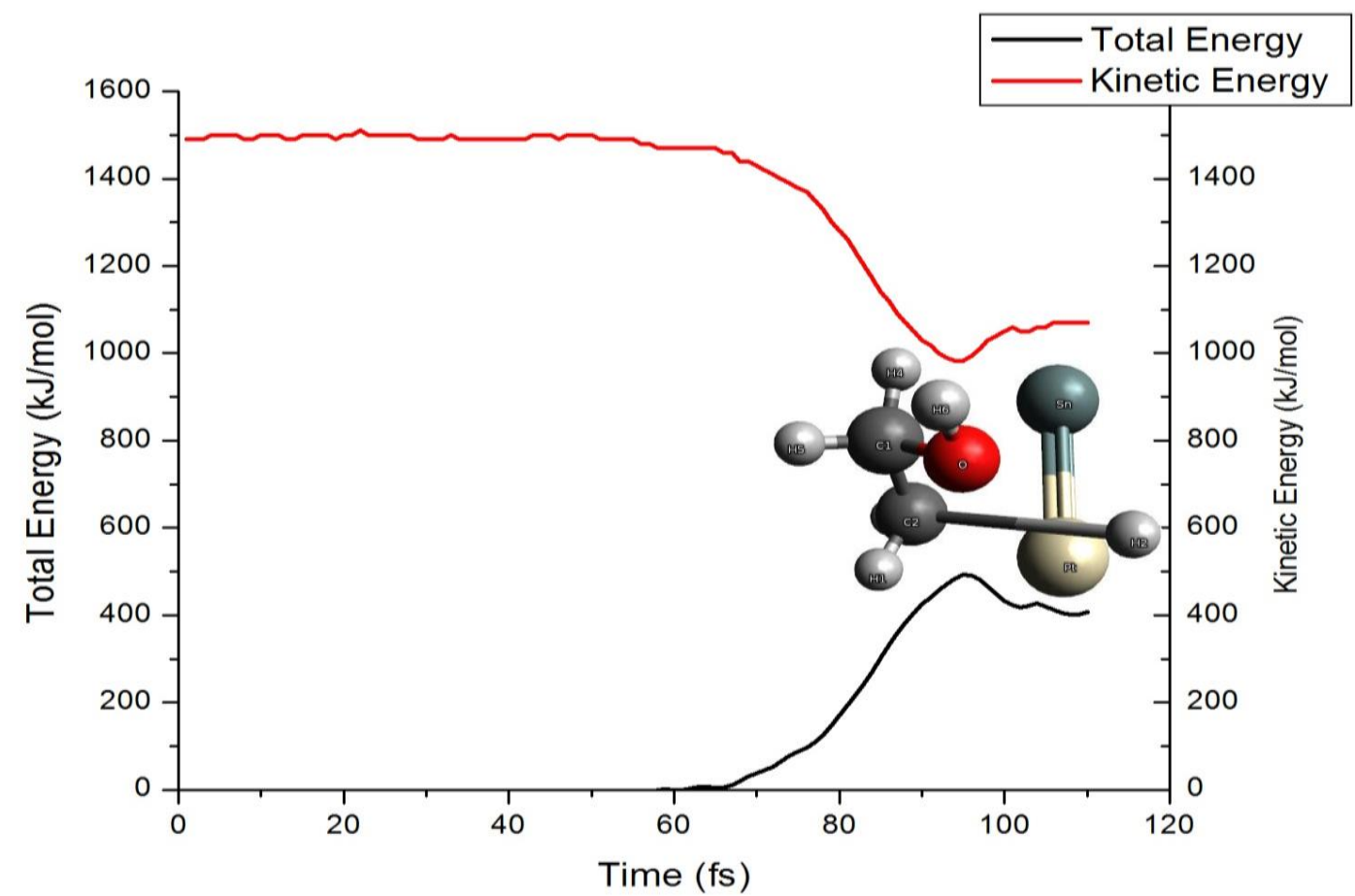

Figure 4. The plot total energy values (left, black line), and kinetic energy (right, red line) is representative of the dynamic interaction when ethanol molecule in the impact has a perpendicular direction to bond $\mathrm{Pt}-\mathrm{Sn}$.

Table 1. The bond length values evolution with the time for each interaction conformation a) b) c) and the results of relevant bond modified due to the interaction between ethanol and Pt-Sn.

\begin{tabular}{|c|c|c|c|}
\hline Time & a) Interaction with $\mathrm{Sn}$ & b) Interaction with $\mathbf{P t}$ & $\begin{array}{l}\text { c) Perpendicular } \\
\text { interaction with Pt-Sn }\end{array}$ \\
\hline 10 & $\mathrm{H}-(1.08)-\mathrm{C}_{2} \mathrm{H}_{4}-(1.46)-\mathrm{OH}$ & $\mathrm{H}-(1.08)-\mathrm{C}_{2} \mathrm{H}_{4}-(1.46)-\mathrm{OH}$ & $\mathrm{H}-(1.10)-\mathrm{C}_{2} \mathrm{H}_{4}-(1.48)-\mathrm{OH}$ \\
\hline 20 & $\mathrm{H}-(1.08)-\mathrm{C}_{2} \mathrm{H}_{4}-(1.46)-\mathrm{OH}$ & $\mathrm{H}-(1.08)-\mathrm{C}_{2} \mathrm{H}_{4}-(1.46)-\mathrm{OH}$ & $\mathrm{H}-(1.09)-\mathrm{C}_{2} \mathrm{H}_{4}-(1.38)-\mathrm{OH}$ \\
\hline 30 & $\mathrm{H}-(1.07)-\mathrm{C}_{2} \mathrm{H}_{4}-(1.45)-\mathrm{OH}$ & $\mathrm{H}-(1.11)-\mathrm{C}_{2} \mathrm{H}_{4}-(1.44)-\mathrm{OH}$ & $\mathrm{H}-(1.11)-\mathrm{C}_{2} \mathrm{H}_{4}-(1.44)-\mathrm{OH}$ \\
\hline 35 & $\mathrm{H}-(1.07)-\mathrm{C}_{2} \mathrm{H}_{4}-(1.46)-\mathrm{OH}$ & $\mathrm{H}-(1.15)-\mathrm{C}_{2} \mathrm{H}_{4}-(1.43)-\mathrm{OH}$ & $\mathrm{H}-(1.09)-\mathrm{C}_{2} \mathrm{H}_{4}-(1.49)-\mathrm{OH}$ \\
\hline 40 & $\mathrm{H}-(1.08)-\mathrm{C}_{2} \mathrm{H}_{4}-(1.47)-\mathrm{OH}$ & $\mathrm{H}-(1.26)-\mathrm{C}_{2} \mathrm{H}_{4}-(1.43)-\mathrm{OH}$ & $\mathrm{H}-(1.05)-\mathrm{C}_{2} \mathrm{H}_{4}-(1.50)-\mathrm{OH}$ \\
\hline 45 & $\mathrm{H}-(1.10)-\mathrm{C}_{2} \mathrm{H}_{4}-(1.49)-\mathrm{OH}$ & $\mathrm{H}-(1.35)-\mathrm{C}_{2} \mathrm{H}_{4}-(1.47)-\mathrm{OH}$ & $\mathrm{H}-(1.10)-\mathrm{C}_{2} \mathrm{H}_{4}-(1.49)-\mathrm{OH}$ \\
\hline 50 & $\mathrm{H}-(1.07)-\mathrm{C}_{2} \mathrm{H}_{4}-(1.45)-\mathrm{OH}$ & $\mathrm{H}-(1.52)-\mathrm{C}_{2} \mathrm{H}_{4}-(1.53)-\mathrm{OH}$ & $\mathrm{H}-(1.05)-\mathrm{C}_{2} \mathrm{H}_{4}-(1.46)-\mathrm{OH}$ \\
\hline 55 & $\mathrm{H}-(1.06)-\mathrm{C}_{2} \mathrm{H}_{4}-(1.53)-\mathrm{OH}$ & $\mathrm{H}-(1.90)-\mathrm{C}_{2} \mathrm{H}_{4}-(1.60)-\mathrm{OH}$ & $\mathrm{H}-(1.11)-\mathrm{C}_{2} \mathrm{H}_{4}-(1.41)-\mathrm{OH}$ \\
\hline 60 & $\mathrm{H}-(1.10)-\mathrm{C}_{2} \mathrm{H}_{4}-(1.57)-\mathrm{OH}$ & $\mathrm{H}-(2.29)-\mathrm{C}_{2} \mathrm{H}_{4}-(1.68)-\mathrm{OH}$ & $\mathrm{H}-(1.05)-\mathrm{C}_{2} \mathrm{H}_{4}-(1.38)-\mathrm{OH}$ \\
\hline 65 & $\mathrm{H}-(1.03)-\mathrm{C}_{2} \mathrm{H}_{4}-(1.62)-\mathrm{OH}$ & $\mathrm{H}-(2.64)-\mathrm{C}_{2} \mathrm{H}_{4}-(1.66)-\mathrm{OH}$ & $\mathrm{H}-(1.11)-\mathrm{C}_{2} \mathrm{H}_{4}-(1.42)-\mathrm{OH}$ \\
\hline 70 & $\mathrm{H}-(1.12)-\mathrm{C}_{2} \mathrm{H}_{4}-(1.71)-\mathrm{OH}$ & $\mathrm{H}-(2.84)-\mathrm{C}_{2} \mathrm{H}_{4}-(1.82)-\mathrm{OH}$ & $\mathrm{H}-(1.06)-\mathrm{C}_{2} \mathrm{H}_{4}-(1.51)-\mathrm{OH}$ \\
\hline 75 & $\mathrm{H}-(1.05)-\mathrm{C}_{2} \mathrm{H}_{4}-(1.60)-\mathrm{OH}$ & $\mathrm{H}-(2.84)-\mathrm{C}_{2} \mathrm{H}_{4}-(1.82)-\mathrm{OH}$ & $\mathrm{H}-(1.10)-\mathrm{C}_{2} \mathrm{H}_{4}-(1.58)-\mathrm{OH}$ \\
\hline 80 & $\mathrm{H}-(1.06)-\mathrm{C}_{2} \mathrm{H}_{4}-(1.50)-\mathrm{OH}$ & $\mathrm{H}-(2.84)-\mathrm{C}_{2} \mathrm{H}_{4}-(1.82)-\mathrm{OH}$ & $\mathrm{H}-(1.08)-\mathrm{C}_{2} \mathrm{H}_{4}-(1.59)-\mathrm{OH}$ \\
\hline 85 & $\mathrm{H}-(1.06)-\mathrm{C}_{2} \mathrm{H}_{4}-(1.50)-\mathrm{OH}$ & $\mathrm{H}-(2.84)-\mathrm{C}_{2} \mathrm{H}_{4}-(1.82)-\mathrm{OH}$ & $\mathrm{H}-(1.08)-\mathrm{C}_{2} \mathrm{H}_{4}-(1.55)-\mathrm{OH}$ \\
\hline 90 & $\mathrm{H}-(1.06)-\mathrm{C}_{2} \mathrm{H}_{4}-(1.50)-\mathrm{OH}$ & $\mathrm{H}-(2.84)-\mathrm{C}_{2} \mathrm{H}_{4}-(1.82)-\mathrm{OH}$ & $\mathrm{H}-(1.18)-\mathrm{C}_{2} \mathrm{H}_{4}-(1.47)-\mathrm{OH}$ \\
\hline 100 & $\mathrm{H}-(1.06)-\mathrm{C}_{2} \mathrm{H}_{4}-(1.50)-\mathrm{OH}$ & $\mathrm{H}-(2.84)-\mathrm{C}_{2} \mathrm{H}_{4}-(1.82)-\mathrm{OH}$ & $\mathrm{H}-(1.71)-\mathrm{C}_{2} \mathrm{H}_{4}-(1.37)-\mathrm{OH}$ \\
\hline 110 & $\mathrm{H}-(1.06)-\mathrm{C}_{2} \mathrm{H}_{4}-(1.50)-\mathrm{OH}$ & $\mathrm{H}-(2.84)-\mathrm{C}_{2} \mathrm{H}_{4}-(1.82)-\mathrm{OH}$ & $\mathrm{H}-(3.21)-\mathrm{C}_{2} \mathrm{H}_{4}-(1.62)-\mathrm{OH}$ \\
\hline 115 & $\mathrm{H}-(1.06)-\mathrm{C}_{2} \mathrm{H}_{4}-(1.50)-\mathrm{OH}$ & $\mathrm{H}-(2.84)-\mathrm{C}_{2} \mathrm{H}_{4}-(1.82)-\mathrm{OH}$ & $\mathrm{H}-(3.38)-\mathrm{C}_{2} \mathrm{H}_{4}-(1.64)-\mathrm{OH}$ \\
\hline
\end{tabular}


Table 2. The bond length values on the initial conformation a) b) c) and the results of relevant bond modified due to the interaction between ethanol and Pt-Sn for the final conformations.

\begin{tabular}{|c|c|c|}
\hline $\begin{array}{l}\text { Bond length of ethanol } \\
\text { fragment }\end{array}$ & Initial $(\AA)$ & Final $(\AA)$ \\
\hline $\mathrm{H}-\mathrm{C}-\mathrm{C}-\mathrm{O}-\mathrm{H}$ & $\mathrm{H}-(1.08)-\mathrm{C}-(1.46)-\mathrm{C}-(1.46)-\mathrm{O}-(0.98)-\mathrm{H}$ & $\mathrm{H}-(1.08)-\mathrm{C}-(1.46)-\mathrm{C}-(1.46)-\mathrm{O}-(0.98)-\mathrm{H}$ \\
\hline $\mathrm{H}-\mathrm{C}-\mathrm{C}-\mathrm{O}-\mathrm{H}$ & $\mathrm{H}-(1.08)-\mathrm{C}-(1.46)-\mathrm{C}-(1.46)-\mathrm{O}-(0.98)-\mathrm{H}$ & $\mathrm{H}-(2.84)-\mathrm{C}-(1.70)-\mathrm{C}-(1.82)-\mathrm{O}-(0.98)-\mathrm{H}$ \\
\hline $\mathrm{H}-\mathrm{C}-\mathrm{C}-\mathrm{O}-\mathrm{H}$ & $\mathrm{H}-(1.08)-\mathrm{C}-(1.55)-\mathrm{C}-(1.53)-\mathrm{O}-(0.99)-\mathrm{H}$ & $\mathrm{H}-(3.38)-\mathrm{C}-(1.53)-\mathrm{C}-(1.64)-\mathrm{O}-(0.99)-\mathrm{H}$ \\
\hline
\end{tabular}

The changes in the values of bond length among atoms are reported in table 1 and 2, where it is noted that the main changes develop at the $\mathrm{CH}_{3}$ of the ethanol, are useful to validate the observation of a bond breaking $\mathrm{C}-\mathrm{H}$ in the ethanol molecule. In b) and c) where principal promotes of break is $\mathrm{Pt}$ atom.

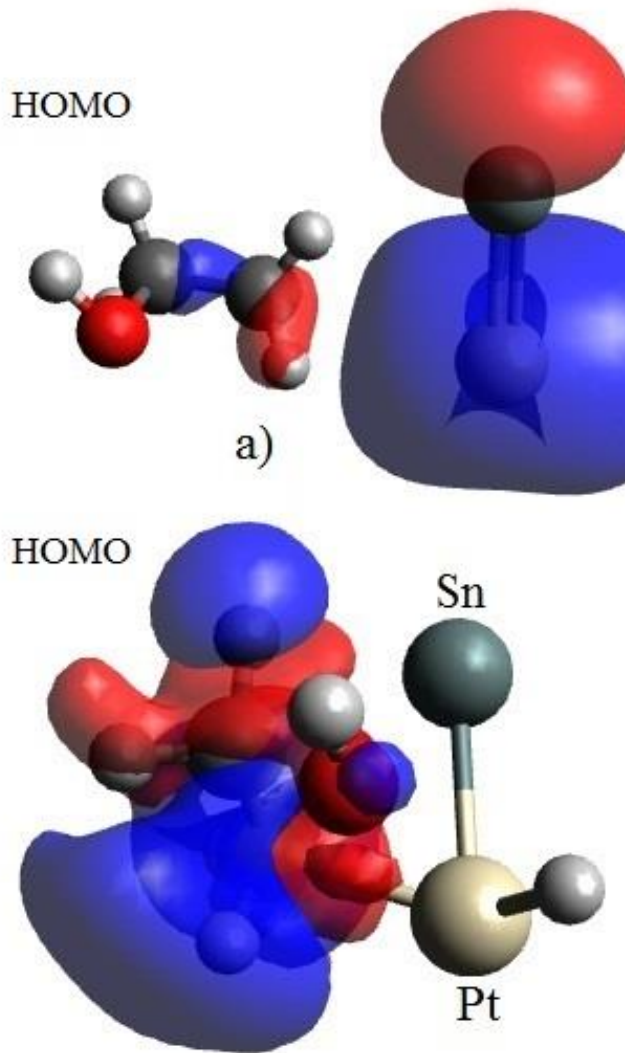

c)
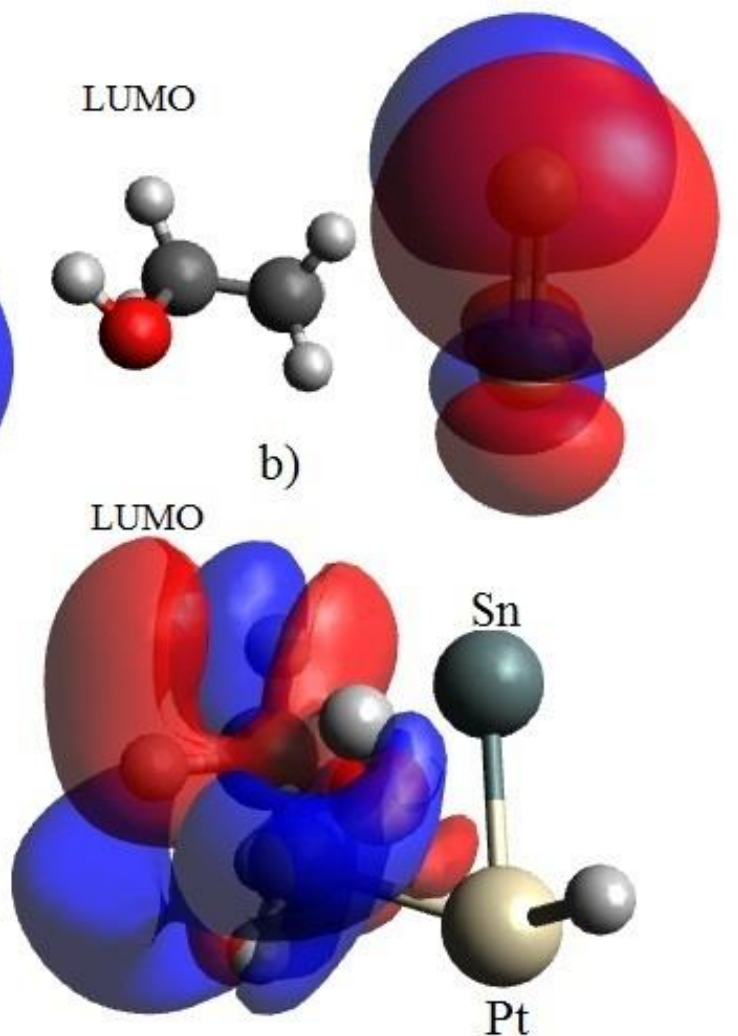

d)

Figure 5. The frontier orbital for initial and final conformation, HOMO is a); c) and LUMO b); d) respectively of the dynamic interaction when ethanol molecule in the impact has a perpendicular direction to bond Pt-Sn.

The molecular orbital analysis shown that frontier orbital before interaction there are a distribution of the d-orbitals only for platinum atom (Pt dzz; Pt dxz; Pt dxx; Pt dxz) and during interaction there are changes in the distribution of platinum, tin, and carbon (Sn py; Pt dyz; Pt dzz; Pt $\mathrm{dxz} ; \mathrm{Pt}$ s; Sn s; and C s).

\section{Conclusion}

The results of this work show the possibility of carrying out ethanol catalysis by means of using a bimetallic Pt-Sn. The energy calculations show that the interaction between ethanol molecule and bimetal produce reactions to themselves, which promote bond breaking over carbon-hydrogen $(\mathrm{C}-\mathrm{H})$ and carbon hydroxyl $(\mathrm{C}-\mathrm{OH})$. The Mulliken population analysis of charge shows the generation of hydrogen ion. The molecules and fragments that were generated as products during the reaction are explained by the analysis of the energies associated with the bond breaking and structural molecular changes of the molecules. Based on the results it is concluded that the relative direction of interaction between the molecules is important, platinum and carbon atoms did not interact directly, avoiding with that the contamination of the catalyst with carbon, according to with the reported experimental results. Finally, the frontier orbital distribution is among platinum, tin, and carbon at the moment of bond breaking. 


\section{Acknowledgements}

IP-Zaragoza thanks TecNM for its financial support project through grant number ITT-201983.

\section{References}

1- G. W. Crabtree and M. S. Dresselhaus MRS BULLETIN 2008, 33, 421-428.

2- Noriko Behling Issues in Science and Technology 2013, 29, 83-90.

3- Faur Ghenciu Current Opinion in Solid State and Material Science 2002, 6, 389-399.

4- P. R. Luciene, P. E. A. Ticianelli, and E. M. J. Assaf, J. Power Sources 2008, 175, 482-489.

5- U. B. J. Demirci, Power Sources 2007, 173, 1118.

6- Walker G M 2010 Bioethanol: Science and technology of fuel alcohol ed Ventus Publishing ApS. 6-17.

7- C. G. Lee, M. Umeda, and I. Uchida, J Power Source 2006, 160, 78-89

8- J. Sun, X. P. Qiu, F. Wu and W. T. Zhu, Int. J. Hydrogen Energy 2005, 30, 437-445.

9- J. Comas, F. Mariño, M. Laborde, N. Amadeo, Chem. Eng. J. 2004, 98, 61-68.

10- N. Athanasios, Fatsikostas and E. Xenophon, Verykios J. Catal. 2005, 225, 439-452.

11- E. D. Wang, J. B. Xu and T. S. Zhao, J. Phys. Chem. C, 2010, 114(23), 10489-10497.

12- H. X. Huang, S. X. Chen, and C. Yuang, J. Power Source 2008, 175, 166-174.

13- E. Antolini, J. Power Source, 2007, 170, 1-12.

14- Y. Wang, Y. Mi, N. Redmon, and J. Holiday, J. Physc. Chem. C Nanomater. Interface 2010, 114,317-326.

15- R. Alcala, J. W. Shabaker, G. W. Huber,
Sanchez-Castillo M A and Dumesic J A, J. Phys. Chem. B, 2005, 109(6), 2074-2085.

16- Z. F. Xu, and Y. Wang, J. Phys. Chem. C Nanomater Interfaces, 2011, 115(42) 20565-20571. 17- I. P. Zaragoza, R. Salcedo, J. Vergara, J. Mol. Model., 2009, 15(5) ,447-51.

18- S. C. Zignania, V, Bagliob, J. J. Linaresa, G. Monforteb, E. R. Gonzaleza, A. S. Aricòb, Electrochim. Acta, 2012, 70, 255- 265.

19- V. Galvita, G. Siddiqi, P. Sun, A. T. Bell, Journal of Catalysis 2010, 271, 209-219.

20- S. S. Gupta, S. Singh, J. Datta, Materials Chemistry and Physics, 2010, 120, 682-690.

21- A. A. El-Shafei, M. Eiswirth, Surface Science, 2010, 604, 862-867.

22- J.-M. Leger, S. Rousseau, C. Coutanceau, F. Hahn, C. Lamy, Electrochim. Acta, 2005, 50, 5118-5125.

23- High-Performance Computational Chemistry Group, NWChem, A Computational Chemistry Package for Parallel Computers, Version 4.1, (2002), Pacific Northwest Na- tional Laboratory, Richland, Washington 99352, U S A .

24- A. D. Becke, Phys. Rev. A, 1988, 38, 3098. 25 - C. Lee, W. Yang and R. G. Parr, Phys. Rev. B 1988, 37, 785 .

26- C. Kramer, A. Spinn, K. R. Liedl, J. Chem. Theory Comput., 2014, 10 (10), 4488-4496. 27- L. Radom, J. A. Pople, J. Am. Chem. Soc., 1970, 92 (16), 4786-4795.

28- Ahmed H. Zewail, J. Phys. Chem., 1996, 100 (31), 12701-12724.

29- I. P. Zaragoza, M. Salas, B. Arista, Mediterr.J. Chem., 2017, 6(2), 42-48.

30- I. P. Zaragoza, L. A. García-Serrano, R. Santamaria, J. Phys. Chem. B, 2005, 109 (2), 705-710. 